\title{
Evaluation of a Transparent Wall System for Residential Construction
}

\author{
Joseph A. Standley ${ }^{1}$ and Ali M. Memari*,2 \\ ${ }^{1}$ Wiss, Janney, Elstner Associates, Inc., 311 Summer Street, Suite 300, Boston, MA 02210, USA \\ ${ }^{2}$ Department of Architectural Engineering and Department of Civil and Environmental Engineering, Penn State \\ University, 219 Sackett Building, University Park, PA 16802, USA
}

\begin{abstract}
A new type of transparent panelized wall system for residential construction has recently been developed that can be used as an alternative to typical wood-frame and other light-frame wall systems. The new wall system is a prefabricated wall panel consisting of a structural steel back-up frame, transparent polycarbonate sheathing, and a curtainwall system that may contain an integrated photovoltaic glazing panel. In this paper, after an introduction to the structural and architectural aspects of system, the thermal and energy performance aspects of this wall system are evaluated based on several criteria. The current configuration of the wall system shows an overall $\mathrm{U}$-factor of $1.585 \mathrm{~W} / \mathrm{m}^{2} \mathrm{k}$. The material and systems analysis using a combination of life-cycle assessment and embodied energy are discussed as well. The embodied energy of the system turns out to be approximately two and a half times that of conventional wood-frame system. The paper provides some concluding remarks regarding the sustainability aspects.
\end{abstract}

Keywords: Building transparent wall, embodied energy, energy analysis, life cycle assessment, photovoltaic, solar energy, thermal performance.

\section{INTRODUCTION}

According to Goetzl and McKeever [1], over 90\% of single-family dwellings in the U.S. are constructed using wood-frame systems. The percent estimate also varies depending on the state, with earthquake prone western states having this as $98 \%$ [2]. $22 \%$ of the total US energy is consumed in such construction, which does not benefit from the solar energy for space heating or cooling that is associated with about $55 \%$ of a residential building's energy consumption [3]. The goal of the study presented here is to evaluate a transparent wall system that is designed to include photovoltaic system as part of glazing for solar energy generation. Prefabricated panelized wall systems $[4,5]$ can offer designers and builders a means to increase sustainability in the residential construction market. Through a preliminary study carried out in 2009-2010 [6] to evaluate potential for new panelized system designs, a new system, referred to here as the Residential GlazedWall Panel System (RGWPS), has been developed. While the paper presented here focuses on thermal and material analysis, more details about structural testing and performance can be found in [7]. The design of the RGWPS is intended to improve upon currently available panelized wall systems appropriate for residential construction by providing the potential for use of solar energy and increased natural lighting.

\footnotetext{
*Address correspondence to this author at the Department of Architectural Engineering and Department of Civil and Environmental Engineering, Penn State University, 219 Sackett Building, University Park, PA 16802, USA;
} Tel: (814) 863-9788; Fax: (814) 863-7304; E-mail: memari@engr.psu.edu
Sustainability is a concept that has existed for centuries, but has only recently come to the forefront of modern construction practice. In its most general form, sustainability has been described as "the ability to meet the needs of the present without compromising the ability of future generations to meet their own needs" [8]. More specifically, sustainability is a term used to define an action, product, or process that strikes an ideal balance between social, environmental, and economic needs.

Although sustainable concepts can be applied to a wide variety of subjects, systems, and industries, it is the construction industry that has adopted perhaps the most prominent approach toward creating a sustainable practice. For example, in 1998, the United States Green Building Council developed a program called LEED (Leadership in Energy and Environmental Design) [9, 10] that not only helped define what constitutes a sustainable building, but also set out to aid designers in creating such buildings. Other building-specific programs have recently been developed as well, including the Green Building Initiative's Green Globes, National Association of Home Builders' National Green Building Program, and the International Living Building Institute's Living Building Challenge.

The level of sustainability that a particular building or building product achieves is a highly subjective matter because sustainability is a complex concept. Opinion varies as to which characteristics weigh more heavily in terms of sustainability. Some experts, for example, may consider energy consumption the most important aspect, while others may consider the toxicity of various chemicals that make up 
the building products. Fortunately, there are several metrics that can be applied in measuring specific qualities of a building or building product that relate in some manner to sustainability. Some of these metrics include energy analysis, material analysis, and life-cycle analysis.

Currently, sustainable design is a major factor in the commercial building industry. However, in residential construction, sustainable concepts have taken longer to implement. Part of the challenge comes from the higher premium that homeowners have to spend up front; although in the long run, that upfront cost is often recuperated through energy cost savings or tax breaks. The RGWPS was developed with the intent to provide an approach to enhance sustainability in residential construction by applying state-ofthe-art, energy-efficient technologies typically found only in commercial construction. Although the initial cost as for other sustainable designs will still be a challenge for the market, more cost-effective technologies will evolve as the proposed system starts to be used (commercialized).

Research on the RGWPS consisted of designdevelopment, structural assessment, and a sustainability analysis that considered material life-cycle, energy performance, and thermal performance [6]. The objective of the part of the research presented here was to evaluate the RGWPS in terms of its level of sustainability as a building system/product. The evaluation was carried out using three different methods: 1) heat transfer and thermal modeling based on software packages of THERM and WINDOW [11]; 2) building energy modeling based on software package Energy 10 [12]; and 3) material and system analysis via life cycle assessment (LCA), considering such aspects as embodied energy, recyclability, and chemical composition. More specifically, the paper discusses the following aspects: 1) heat transfer analysis through the proposed wall to evaluate the thermal efficiency and condensation resistance; 2) determine base-line thermal performance data (thermal conductivity/resistance and solar heat gain coefficient) for the proposed wall system for comparison with published values for the conventional wood-frame wall; 3 ) evaluate the energy performance of a house that uses the proposed system; 4) evaluate the performance of glazing integrated PV system; and 5) perform LCA to evaluate the embodied energy of the material used in the proposed wall system.

\section{DESIGN DEVELOPMENT}

The overall concept of RGWPS was to introduce environmentally friendly and sustainable properties to a prefabricated transparent wall panel by considering the following desirable attributes:

- Maximize natural lighting to reduce electricity demand.

- Maximize solar heat gain during cold months.

- Improve thermal efficiency by using an insulated glazing (IG) unit.

- Generate electricity using photovoltaic system.

- Utilize highly reusable or recyclable materials.

- Utilize a panelized system that reduces waste and increases construction efficiency.
- Improve indoor environment for building occupants.

In consideration of the desirable characteristics, the initial concept of RGWPS was developed using a combination of a load-bearing steel backup frame and an aluminum and glass curtain-wall. The steel backup frame is constructed of $51 \mathrm{~mm}$ by $102 \mathrm{~mm}$ by $6.4 \mathrm{~mm}$-thick structural steel tube sections (HSS). The frame consists of top, midheight, and bottom horizontal members with vertical columns on either side, creating a $1.2 \mathrm{~m}$ wide by $2.4 \mathrm{~m}$ tall rectangular panel. A $51 \mathrm{~mm}$ by $102 \mathrm{~mm}$ wood nailer is attached along the top of the upper horizontal member to provide nail or woodscrew connectivity between the panel and adjacent building elements. The conceptual design of the RGWPS is illustrated in Figs. (1 and 2).

Lateral load resistance of the RGWPS is provided by a combination of the backup frame and a rigid sheathing panel. The sheathing panel consists of a single $1.2 \mathrm{~m}$ by $2.4 \mathrm{~m}$ by $6.4 \mathrm{~mm}$-thick polycarbonate sheet [13]. Polycarbonate sheet is available with various levels of transparency, abrasion resistance, or other specialized properties that can be chosen by the designer or manufacturer. The polycarbonate sheet is sandwiched between the steel backup frame and custom aluminum curtain-wall framing members. Self-drilling screws are installed through the curtain-wall framing and polycarbonate sheathing into the steel frame.

Polycarbonate was chosen as the sheathing material for several reasons. First, polycarbonate is transparent, thereby allowing natural light to pass through the wall system into the building interior. Likewise, the transparency offers building occupants unobstructed views to the outdoors. Both of these characteristics were identified as desirable attributes for a sustainable wall system. Furthermore, polycarbonate is durable and has a high strength-to-weight ratio, so it has potential for use as a structural element. Its high impact strength can also help improve security and deter break-ins, while low-flammability variations can reduce fire risks.

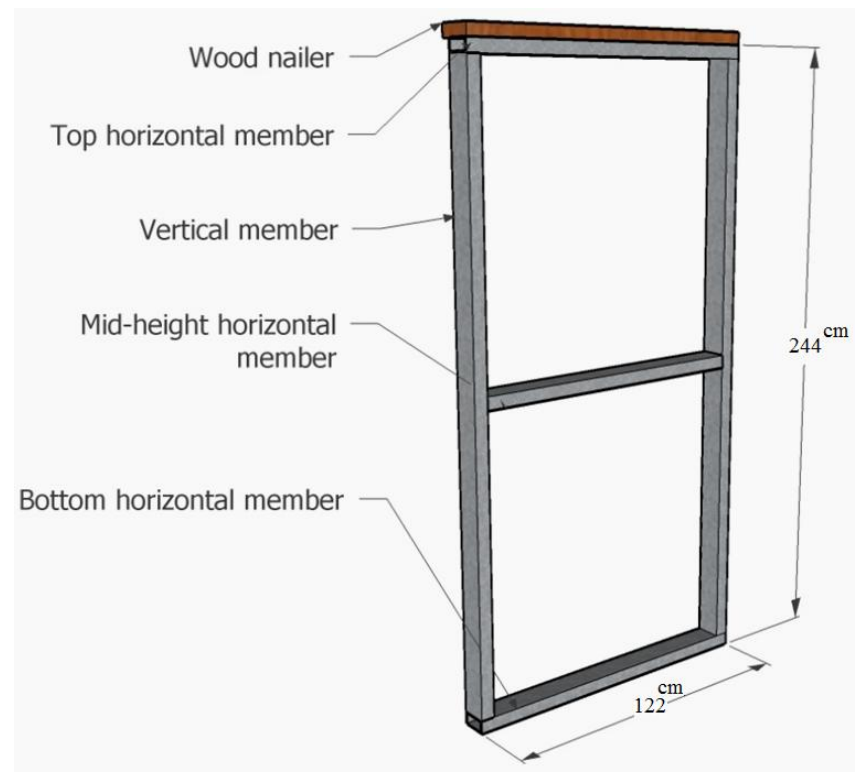

Fig. (1). Rendering of RGWPS Backup Frame. 


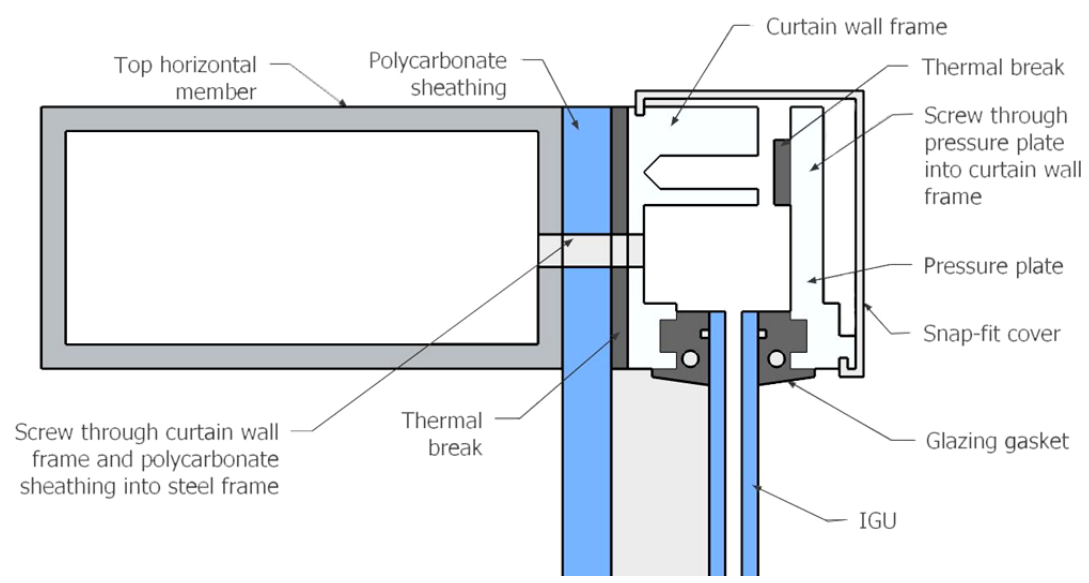

Fig. (2). Detail of cross-section through top of RGWPS.

Finally, polycarbonate is not an organic material, so it is inherently resistant to mold and rot.

\section{THERMAL ANALYSIS}

Thermal performance of the RGWPS was modeled using a combination of the THERM and WINDOW software packages developed by Lawrence Berkley National Laboratories [11]. These software packages work together to calculate the overall product thermal conductivity (U-factor) and solar heat gain coefficient (SHGC) for a given window unit (glazing and frame). These two values are an effective means of comparing the thermal properties of the RGWPS to standard consumer-grade window systems.

In order to simplify the THERM and WINDOW models and address those items still under development, several assumptions about the RGWPS were required. For example, the overall geometry of the RGWPS is defined, but the shape of the custom extruded aluminum glazing mullion is not. Other assumptions include environmental conditions, materials, or glazing types. Tables $\mathbf{1 , 2}$ and $\mathbf{3}$ summarizes the major modeling assumptions for the RGWPS and Fig. (3) shows the geometry of the RGWPS as modeled in THERM.

The glazing system within the RGWPS also remains at the development stage, and the design of the RGWPS frame allows the manufacturer or homeowner to specify a variety of glazing products that fit within its geometry [14]. It is important to note that the choice of glazing system will play a major role in the overall thermal performance of the RGWPS. It was the initial design intent, however, to utilize an integrated photovoltaic glazing system. The glazing system was therefore modeled to resemble ASI Glass by Schott Solar, which is an insulated glazing unit with an integrated PV film. Schott Solar publishes technical data about their ASI Glass in the Sizes and Specifications data sheet [15].

Every effort was made to create a glazing system in WINDOW that accurately represents the published

Table 1. THERM and WINDOW modeling assumptions for RGWPS.

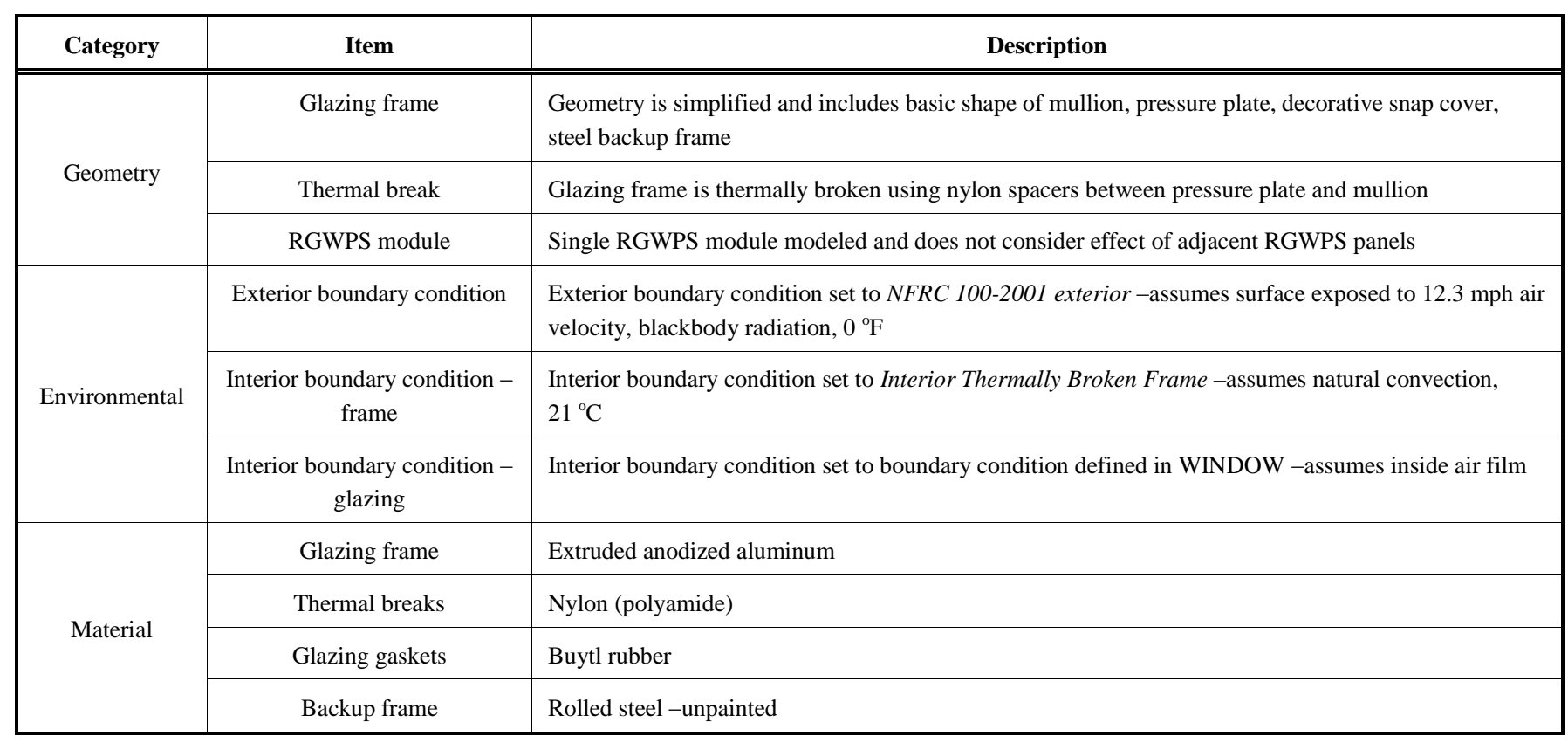


Table 2. THERM model material properties.

\begin{tabular}{|c|c|c|c|}
\hline Element & Material & Conductivity W/m ${ }^{2} \mathbf{K}$ & Emmisivity \\
\hline \hline Glazing Frame & Anodized aluminum & 777.4 & 0.8 \\
\hline Thermal Break & Nylon (polyamide) & 0.82 & 0.9 \\
\hline Gaskets & Butyl rubber & 0.79 & 0.9 \\
\hline Structural Frame & Steel (rolled, ground) & 164.1 & 0.6 \\
\hline Sheathing & Polycarbonate & 0.66 & 0.9 \\
\hline
\end{tabular}

Table 3. THERM model boundary conditions.

\begin{tabular}{|c|c|c|c|c|}
\hline Location & Boundary Condition & Temp. $^{\circ} \mathbf{C}$ & Film Coefficient W/m ${ }^{2} \mathbf{K}$ & Radiation Model \\
\hline \hline $\begin{array}{c}\text { Exterior Surface of Frame } \\
\text { and Glazing }\end{array}$ & NFRC 100-2001 Exterior & -17.8 & 26.0 & Black Body \\
\hline Model Extents & Adiabatic & 0 & 0.0 & $\mathrm{n} / \mathrm{a}$ \\
\hline Frame Interior & $\begin{array}{c}\text { Interior Thermally Improved Frame (Convection } \\
\text { only) }\end{array}$ & 21 & 3.11 & $\begin{array}{c}\text { Automatic Enclosure } \\
\text { Model }\end{array}$ \\
\hline
\end{tabular}
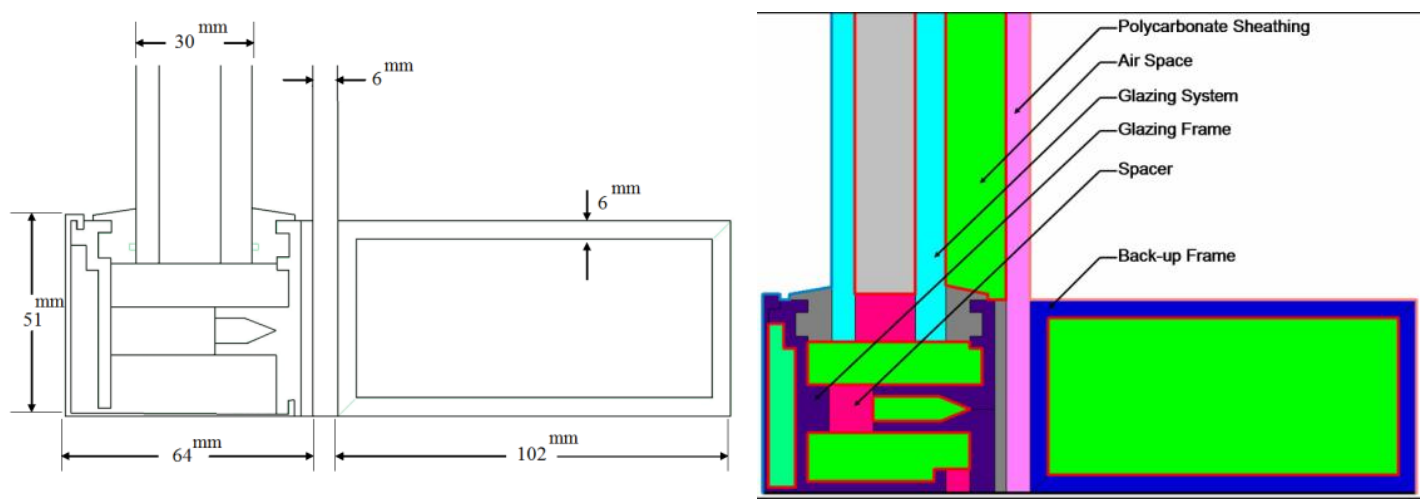

Fig. (3). RGWPS head and sill geometry as modeled in THERM. Jamb geometry is similar.

properties of ASI Glass; however, the integrated PV film presents a problem because WINDOW did not currently support such systems at the time of the study. The PV film alters the U-factor, light transmission, and solar heat gain coefficient of the glazing module. After several trial-anderror iterations, a glazing system was developed for the WINDOW and THERM model that had a U-factor and geometry similar to ASI Glass. Table 4 compares the properties of the modeled glazing system to those of $A S I$ Glass.

The THERM analysis of the RGWPS head, jamb, and sill cross-sections produced two valuable sets of data. First, U-factors for the cross-section and edge of glazing were calculated. These values, listed in Table $\mathbf{5}$, take into

Table 4. THERM and WINDOW modeling assumptions for RGWPS glazing system.

\begin{tabular}{|c|c|c|}
\hline Item & ASI Glass & THERM/WINDOW Model \\
\hline \hline Front Glass & $6 \mathrm{~mm}$ & $6 \mathrm{~mm}$ \\
\hline Air Space & $16 \mathrm{~mm}$ (xenon filled) \\
\hline Back Glass & $8 \mathrm{~mm}$ & $1.215 \mathrm{Wm} / \mathrm{m}^{2} \mathrm{k}$ \\
\hline U-factor & $1.2 \mathrm{~W} / \mathrm{m}^{2} \mathrm{k}$ & $27.6 \%$ \\
\hline Solar Heat Gain Coefficient & $10 \%$ & $\mathrm{n} / \mathrm{a}$ \\
\hline Visible Transmittance & $10 \%$ & \\
\hline
\end{tabular}


consideration frame geometry, boundary conditions, material composition, and edge effects from the glazing system. As expected due to geometric symmetry, the U-factors for the head and sill are nearly identical. The jamb U-factor is slightly different because the aluminum glazing frame section at the jamb spans to an adjacent RGWPS unit (which was not modeled). The thermal gradient through each cross section was also determined for head, jamb and sill. Fig. (4) shows typical isotherm lines and thermal gradient results for the sill section. In the thermal gradient sketch, darker colors at the left (exterior surface) represent lower temperature, while lighter colors at the right (interior surface) represent higher temperatures. It is noted that the coldest portion at the interior of each cross-section occurs at the inside corner intersection between the PC sheathing and steel backup frame. Furthermore, the abrupt change in temperature, marked by the sharp transition from dark to light colors indicates the effectiveness of the nylon spacers that act as thermal breaks between portions of the aluminum glazing frame.

Results from the THERM analysis were added to the WINDOW model in order to calculate a whole-product U-factor and SHGC for the RGWPS. The whole-product U-factor takes into consideration the U-factor of the head, sill, and jamb calculated in THERM, as well as the center of glazing U-factor calculated in WINDOW. The wholeproduct U-factor calculated by WINDOW was $1.585 \mathrm{~W} / \mathrm{m}^{2} \mathrm{k}$, while the solar heat gain coefficient turned out to be 0.248 .

The thermal performance of the RGWPS, based on computer simulations in THERM and WINDOW indicates that it is relatively thermally efficient when compared to standard consumer-grade residential windows. For example, the RGWPS falls within the published range of values for typical residential windows manufactured by Marvin, Pella, and Loewen [6].

Since the RGWPS is a window and wall contained in a single panel, it is just as important to understand its thermal performance as a wall system. Another means of evaluating the thermal performance of the RGWPS, therefore, is to compare its R-value (inverse of the U-factor) to that of typical wall systems. The RGWPS R-value is $0.631 \mathrm{~m}^{2} \mathrm{k} / \mathrm{W}$, which is simply the inverse of the U-factor calculated in WINDOW. This value can be considered a whole-wall $\mathrm{R}$-value because the RGWPS is intended to act as a complete wall assembly, replacing all other typical wall materials wherever it is installed.

For comparative purposes, the whole-wall R-values for various wall constructions were calculated [6] using the Oak Ridge National Laboratory's Online Whole Wall R-value Calculator [16]. The calculator takes into consideration wall geometry and material selection, and calculates the wholewall and clear-wall R-values. The clear-wall R-value is a simple calculation based solely on the thermal conductivity of each wall material and its thickness. The whole-wall $\mathrm{R}$-value is more complex, and is based on a pre-defined residential building with typical elements such as doors, windows, partitions, and floors. The RGWPS has an R-value $\left(0.631 \mathrm{~m}^{2} \mathrm{~K} / \mathrm{W}\right)$ that is $150 \%$ lower than a conventional wall with $50 \mathrm{~mm} \times 100 \mathrm{~mm}$ at $400 \mathrm{~mm}$ o. c. studs and R-19 fiberglass insulation.

Table 5. RGWPS U-factors calculated by THERM.

\begin{tabular}{|c|c|}
\hline Section & U-factor $\mathbf{W} / \mathbf{m}^{2} \mathbf{k}$ \\
\hline \hline Head & 4.43 \\
\hline Sill & 4.42 \\
\hline Jamb & 3.97 \\
\hline
\end{tabular}

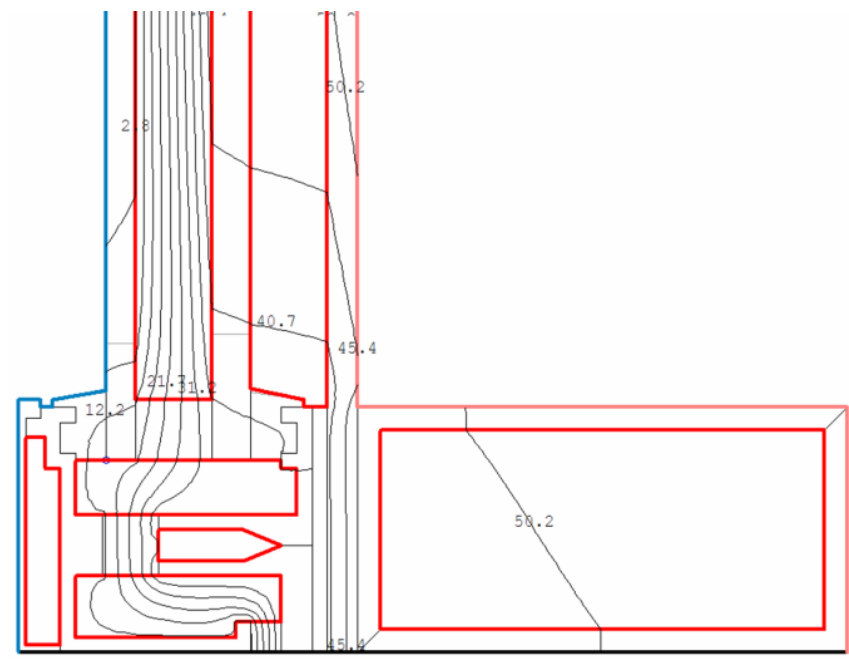

(a) Isotherm lines

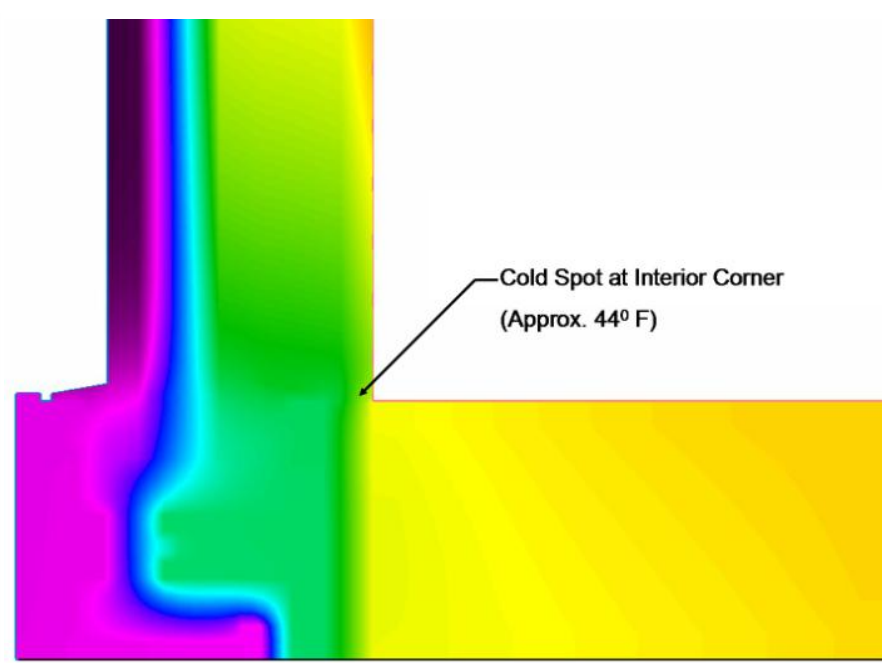

(b) Thermal gradient

Fig. (4). Typical isotherm lines and thermal gradient through the sill section. 


\section{ENERGY ANALYSIS}

The energy performance of the RGWPS was modeled using the Energy-10 software package developed by the National Renewable Energy Laboratory's (NREL) Center for Building and Thermal Systems, the Sustainable Buildings Industry Council, Lawrence Berkeley National Laboratory, and the Berkeley Solar Group [12]. Energy-10 is a useful tool that allows the user to make a side-by-side energy comparison between two different building models. An energy evaluation is an effective means of comparing the overall effect of the RGWPS on a house's energy consumption versus that of traditional windows and walls.

The Energy-10 software is typically used to compare standard construction to multiple energy-efficient strategies working in conjunction. For example, the energy-efficient model may contain more efficient HVAC systems, more thermally efficient windows, and different wall and roof assemblies that provide better insulation. In order to evaluate the overall effect of the RGWPS, it must be isolated from any other energy-efficient design changes. Therefore, models for both the reference case and energy-efficient case must be identical, with the exception of the RGWPS replacing one wall in the energy-efficient case. The actual layout, construction, and mechanical systems contained in the models are of lesser importance because the purpose of this analysis is to understand the relative effect the RWGPS would have on building energy requirements.

The models created for the Energy-10 analysis were based on a simple two-story wood-frame house located in the Boston, Massachusetts climate zone. The house features a rectangular footprint measuring $12.2 \mathrm{~m}$ by $7.6 \mathrm{~m}$, resulting in $92.9 \mathrm{~m}^{2}$ per floor, or $185.8 \mathrm{~m}^{2}$ total. The house is oriented with its long axis running north to south. Since for energy performance evaluation unit costs are needed, the analysis used applicable costs at the time of the study. Energy costs were those based on the actual 2009 electric and gas costs for the town of Belmont, Massachusetts, which is a suburb of Boston. Since the study is comparative (with respect to conventional wood-frame), the results can be considered useful regardless of the year the cost analysis was done. Table 6 lists the major characteristics of the model.

The energy-efficient case, named the RGWPS case, includes the addition of 6 RGWPS modules to the south wall. These modules replace the four windows along the south elevation with RGWPS modules that are both larger in size and feature different energy and electrical characteristics. The RGWPS module is modeled as a window system in Energy-10 in order to accurately account for the day-lighting improvements the system offers. Physical properties for the glazing and frame are based on results of the THERM modeling. Energy-10 has an integrated whole-product U-factor calculator that considers the glazing system and frame U-factors. The whole-product U-factor calculated by Energy-10 is $1.67 \mathrm{~W} / \mathrm{m}^{2} \mathrm{~K}$, which varies by less than $1 \%$ from the U-factor of $1.68 \mathrm{~W} / \mathrm{m}^{2} \mathrm{~K}$ previously calculated in THERM/WINDOW.

The electrical properties of the integrated photovoltaic system were based on values for ASI Glass, which are published by its manufacturer, Schott Solar [15]. For background information on the effect of electricity produced by photovoltaic systems on energy performance of residential and commercial buildings, the works discussed by Perez et al. [17] and Miyazaki et al. [18] are suggested. The glazing-integrated PV system measures approximately $2.3 \mathrm{~m}$ by $1 \mathrm{~m}$ and has a rated power output of $122 \mathrm{Watts}(\mathrm{Wp})$ at 68 Volts (V). Six of these RGWPS panels produce a PV array with a rated power output of $0.7 \mathrm{kWp}$, which is set at a tilt of $90^{\circ}$ (vertical) with an azimuth of $180^{\circ}$ (south-facing). The electrical inverter required to convert the PV-produced energy from direct-current (DC) to alternating current (AC) was chosen to have an average efficiency of $85 \%$.

The Energy-10 analysis compared a reference case model to an RGWPS model where all items were identical with exception of the addition of RGWPS modules along the south façade. The analysis included a thermal and day lighting analysis of the reference case and a thermal, day lighting, and photovoltaic analysis of the RGWPS case. The Energy-10 analysis provided many useful charts and tables for comparing the two cases. The most important set of data relates to the total energy use of each building over the course of one year. Here, the reference case had a total energy use of $939.1 \mathrm{MJ} / \mathrm{m}^{2}$, which is $174,500 \mathrm{MJ}$ for the entire $185.8 \mathrm{~m}^{2}$ house. In contrast, the RGWPS had a total energy use of $977.8 \mathrm{MJ} / \mathrm{m}^{2}$, or $181,700 \mathrm{MJ}$ for the entire house, which is $4 \%$ increase in energy over the reference case.

A comparison of annual energy use is and tabulated in Table 7. This data is separated into five categories; heating, cooling, lights, other, and total. The "other" category includes fans, hot water, and electrical plug loads. The data indicates that the RGWPS case results in an approximate 7\% increase in heating energy use and an approximate $14 \%$

Table 6. Energy-10 model characteristics.

\begin{tabular}{|c|c|c|}
\hline Item & Description & Comments \\
\hline \hline HVAC system & Gas furnace with direct-expansion cooling & $80 \%$ heating efficiency \\
\hline Windows & $\begin{array}{c}4060 \text { double-glaze low-e windows with wood } \\
\text { frame }\end{array}$ & $\begin{array}{c}\text { 4 windows on north and south walls, 6 windows on east and west walls. Energy- } \\
10 \text { database U-factor 0.268 }\end{array}$ \\
\hline Walls & $2 \times 6$ wood frame with fiberglass insulation & Energy-10 database R-value 17.69 \\
\hline Floors & $2 \times 10$ wood frame with fiberglass insulation & Energy-10 database R-value 15.19 \\
\hline Roof & Attic roof, R-60 & Energy-10 database R-value 60.18 \\
\hline
\end{tabular}


decrease in cooling energy use over the reference case. The photovoltaic system included in the RGWPS, which affects the "other" category, resulted in a 3\% decrease in energy use. Day lighting provided by the RGWPS did not affect the overall lighting energy use over the base case.

The annual energy usage analysis results typically fall within expected ranges. For example, the THERM and WINDOW analysis of the RGWPS indicate that the RGWPS has a much lower R-value compared to the wood-frame wall systems it is intended to replace. As a result, a house with the RGWPS installed has a given segment of wall that provides less thermal insulation versus typical construction and therefore heating loads will be greater in the RGWPS case.

The Energy-10 analysis shows that the RGWPS and reference case have the exact same lighting energy use. To explain this, one needs to consider a single RGWPS panel provides a glazed opening measuring $3 \mathrm{~m}^{2}$, so a series of six panels provides $17.8 \mathrm{~m}^{2}$ of glazed opening. In the Energy-10 model, this row of six RGWPS panels replaced four standard windows on the south wall each with approximately $1.2 \mathrm{~m}^{2}$ of glazed opening, or $4.8 \mathrm{~m}^{2}$ total. The RGWPS therefore provided $270 \%$ more glazed area on the south wall. However, this is only an increase in glazed area of $54 \%$ when compared to the total glazed area for all four walls. This smaller increase in glazed area, coupled with the lower visible light transmittance (due to integrated PV film) of the ASI glass within the RGWPS explains why it does not affect the lighting demands.

\section{MATERIAL ANALYSIS}

Sustainability of building materials and systems is a very complex subject because it requires input from a diverse set of factors such as chemistry, ecology, and sociology. There are numerous methods and techniques for assessing the level of sustainability of a particular material, system, or process. For example, there are commercial software packages that are used to perform lifecycle assessment (LCA) on building materials or products. This LCA software often includes many of the wide range of factors that must be considered in a sustainability analysis. Conversely, there are other more simple methods that analyze only specific aspects of the material or system, such as embodied energy or ease of recycling. The following sections provide a comparative analysis of the RGWPS and typical light-frame wall construction using an LCA software packaged called ATHENA, as well as a more simplistic methods.

\section{ATHENA Impact Estimator is a life-cycle analysis}

software package jointly developed by the Athena Institute and Morrison Hershfield Consulting Engineers [19]. The software allows for side-by-side comparisons between various products and materials. The Athena analysis carried out in this study compares the environmental impact of a single RGWPS panel measuring $1.2 \mathrm{~m}$ by $2.4 \mathrm{~m}$ to that of a typical wood-frame wall with the same dimensions.

There were several design assumptions required to perform the Athena analysis for the RGWPS because it is a unique wall system that uses unconventional materials. For example, Athena does not include material data for polycarbonate. Therefore, the polycarbonate sheathing panel was modeled as polypropylene, which is a similar, but not identical, petroleum-based thermoplastic. Additional assumptions included the glazing material, size of the glazed opening, and dimensions of the aluminum glazing frame. Furthermore, the analysis does not consider the integrated thin-film PV element inside the glazing. The model characteristics for the wood-frame wall required far fewer assumptions because the software includes pre-defined assemblies for wood-frame walls. Two wood-frame wall cases were evaluated; one solid wall panel with no window openings, and one wall panel with a single window.

The Athena software compares various measurement metrics such as energy consumption, smog potential, and human health respiratory effects. These metrics are broken into four categories of the product life-cycle: manufacture, construction, maintenance, and end-of-life. The construction and end-of-life categories typically featured very small impact results compared to those for the manufacture and maintenance categories. A summary of the results, excluding data for the construction and end-of-life categories, is given in Table 8.

In general, the manufacturing and maintenance processes for the RGWPS produced significantly higher results in all categories. This is expected because the RGWPS uses highly refined materials that require intensive manufacturing processes and the glazing system requires more frequent cleaning and maintenance than vinyl siding. The data also shows the effect of adding a window to the wood-frame wall. Here, the window increases both manufacturing and maintenance results in nearly all categories over the standard wood-frame wall. This is expected because the PVC clad window has highly refined materials and requires maintenance over its lifespan. Finally, the data shows zero maintenance impact for the standard wood-frame wall. This is highly unlikely as all wall systems require some level of

Table 7. Summary of annual energy use.

\begin{tabular}{|c|c|c|c|}
\hline Category & Reference Case Energy Use $\left(\mathbf{M J} / \mathbf{m}^{2}\right)$ & RGWPS Case Energy Use $\left(\mathbf{M J} / \mathbf{m}^{2}\right)$ & Percent Difference $(\%)$ \\
\hline \hline Heating & 667.7 & 716.5 & 6.8 \\
\hline Cooling & 27.2 & 23.8 & -14.3 \\
\hline Lights & 21.6 & 21.6 & 0.0 \\
\hline Other & 221.4 & 215.8 & -2.6 \\
\hline Total & 939.1 & 977.8 & 3.9 \\
\hline
\end{tabular}


Table 8. ATHENA material comparison results. Higher numbers indicate greater environmental impact.

\begin{tabular}{|c|c|c|c|c|c|c|}
\hline \multirow[b]{2}{*}{ Sustainability Category } & \multicolumn{2}{|c|}{ RGWPS } & \multicolumn{2}{|c|}{ Wood-frame } & \multicolumn{2}{|c|}{ Wood-frame w/ Window } \\
\hline & Manuf. & Maint. & Manuf. & Maint. & Manuf. & Maint. \\
\hline Weighted Resource Use (kg) & 13,000 & 1,000 & 2,000 & 0 & 5,000 & 2,500 \\
\hline Solid Waste (kg) & 500 & 50 & 50 & 0 & 75 & 50 \\
\hline HH Respiratory Effects (kg PM2.5) & 17,500 & 3,000 & 500 & 0 & 4,000 & 2,500 \\
\hline Global Warming (kg CO2) & 80,000 & 10,000 & 9,000 & 0 & 30,000 & 15,000 \\
\hline Eutrophication $(\mathrm{kg} \mathrm{N})$ & 4,500 & 250 & 500 & 0 & 1,750 & 800 \\
\hline Acidification (moles $\mathrm{H}+)$ & $1,900,000$ & 200,000 & 200,000 & 0 & 600,000 & 300,000 \\
\hline
\end{tabular}

maintenance over their intended lifespan.

An alternative means of assessing a material or system's sustainability is to follow a more philosophical or qualitative approach. One such method is described in Sustainable Construction: Green Building Design and Delivery [20]. The method, derived from The Natural Step [21], consists of the following major goals [20]: (a) The materials used are nonpersistent and nontoxic and produced from reused, recycled, renewable, or abundant (in nature) sources; (b) The extraction of renewable or abundant materials is based on using renewable energy and protecting the nature; and (c) Design and use of materials in the building will consider criteria such as deconstruction, reuse, durability, minimize solid waste, reuse of water, reuse of left-over material offsite, and recycling or composting of solid waste that cannot be reused.

Table 9 is a side-by-side comparison of the RGWPS and wood-frame wall systems using the criteria listed above. Evaluating the RGWPS using these criteria yields a significantly different result than the ATHENA life-cycle

Table 9. Material analysis using The Natural Step method.

\begin{tabular}{|c|c|c|}
\hline & Item & Commentary \\
\hline \multirow{5}{*}{$\sum_{\simeq}^{\infty}$} & Steel Back-Up Frame & Structural steel generally $96 \%$ recycled content \\
\hline & Polycarbonate Sheathing & $\begin{array}{l}\text { Plastic building products typically not recycled. Polycarbonate likely has high embodied energy. Place of } \\
\text { manufacture likely far from job site }\end{array}$ \\
\hline & Aluminum Glazing Frame & Aluminum generally $65 \%$ recycled content \\
\hline & Glazing System & PV-integrated glazing system not easy to recycle \\
\hline & Other & $\begin{array}{l}\text { - } \\
\text { - } \\
\text { - } \\
\text { PGWPS easily deconstructed into constituent parts } \\
\text { - }\end{array}$ \\
\hline \multirow{6}{*}{ 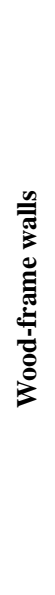 } & Wood Studs/ Sheathing & $\begin{array}{l}\text { - } \quad \text { FSC certified wood is a renewable and abundant resource } \\
\text { - Wood is easily reused, but rarely recycled } \\
\text { - Wood is a common building material and available in almost all local markets, thus it likely has less } \\
\text { travel distance from place of manufacture to jobsite }\end{array}$ \\
\hline & Insulation & Cellulose insulation is $80-85 \%$ recycled content. Soy-based foam insulations are highly renewable \\
\hline & Gypsum Wallboard & $\begin{array}{l}\text { Some gypsum wallboard contains high recycled content. Used drywall not easily recycled due to paints and } \\
\text { adhesives applied to the surface }\end{array}$ \\
\hline & Paint & Not recyclable or reusable. Some paint is toxic and not easily disposable \\
\hline & Exterior Finish & $\begin{array}{l}\text { - } \quad \text { Vinyl siding rarely recycled, not renewable material } \\
\text { - } \quad \text { Aluminum siding easily recycled (typically } 65 \% \text { recycled content) }\end{array}$ \\
\hline & Other & $\begin{array}{l}\text { - Wood-frame walls built on site with less quality control and significant construction waste } \\
\text { - } \quad \text { Walls not easily disassembled into constituent parts. Materials have little reuse value } \\
\text { - } \quad \text { Windows can be salvaged and reused }\end{array}$ \\
\hline
\end{tabular}


analysis because it considers items not covered by the software. These items include, among others, the prefabricated, panelized nature of the RGWPS that can drastically reduce both production and construction waste, as well as easy deconstruct-ability of an RGWPS panel.

A third and final means of assessing sustainability of product is to evaluate the embodied energy of its constituent parts. Embodied energy is defined as the total energy consumed in the acquisition and processing of raw materials, including manufacturing, transportation, and final installation [20]. Embodied energy is typically measured in terms of energy per unit mass or energy per unit volume. Calculating the total embodied energy of a building product requires an understanding of all the materials (and their mass), that are used to produce the product.

Embodied energy data is published by a variety of sources. The two sources used in this analysis include Sustainable Construction: Green Building Design and Delivery [20] and the Victoria University of Wellington's Centre for Building Performance Research [22]. The total embodied energy in a single RGWPS panel was calculated to be $4,558 \mathrm{MJ}\left(1519 \mathrm{MJ} / \mathrm{m}^{2}\right.$ of wall), while the total embodied energy in a single $1.2 \mathrm{~m} \mathrm{x} 2.4 \mathrm{~m}$ section of wood-frame wall was $1,369 \mathrm{MJ}$ ( $456 \mathrm{MJ} / \mathrm{m}^{2}$ of wall). The RGWPS therefore has $233 \%$ more embodied energy than the wood-frame wall. Table 10 summarizes the embodied energy calculations.

An important note is that the embodied energy calculations for the wood-frame wall do not consider any windows located within that wall segment. The addition of a window to the calculation will increase the total embodied energy of the wall due to the materials contained in the window. It can therefore be assumed that the overall embodied energy in a complete wood-frame wall that has several windows will fall above the $456 \mathrm{MJ} / \mathrm{m}^{2}$ of wall calculated above. In the end, however, the addition of windows to the wood-frame wall will likely not be enough to increase its overall embodied energy to a level on par with the RGWPS.

\section{SUMMARY AND CONCLUSIONS}

The thermal performance modeling indicates that the RGWPS, when considered a window assembly, provides an overall $\mathrm{U}$-factor $1.585 \mathrm{~W} / \mathrm{m}^{2} \mathrm{k}$, which falls within the range of typical residential windows. When considered a wall assembly, the RGWPS provides an overall R-value of $0.631 \mathrm{~m}^{2} \mathrm{k} / \mathrm{W}$, which is significantly lower than the conventional residential wall system.

The energy performance modeling indicates that the model house with six RGWPS panels will require approximately $4 \%$ more energy to operate, but at a 3\% lower overall cost than the reference model. It is important to note, however, that these results would likely vary significantly if more RGWPS panels were used. For example, doubling the number of RGWPS panels decreases the cumulative wall $\mathrm{R}$-value but increases the amount of glazed openings and the size of the PV system. It is clear that a much more in-depth analysis be performed that considers other building configurations, geographic locations, and amount of RGWPS panels used.

The multi-tiered approach to the material sustainability analysis showed that in terms of life-cycle impact, the RGWPS is less sustainable than wood-frame walls. However, when considering other factors such as construction waste and recycling of materials, the RGWPS

Table 10. Embodied energy in RGWPS and Wood-frame wall.

\begin{tabular}{|c|c|c|c|c|}
\hline Item & Material & Mass in System (kg) & $\begin{array}{c}\text { Material Embodied Energy } \\
\text { (MJ/kg) }\end{array}$ & $\begin{array}{c}\text { Total Embodied Energy } \\
(\mathbf{M J})\end{array}$ \\
\hline \hline Back-up Frame & Recycled steel & 98 & 8.9 & 872 \\
\hline Glazing Frame & Recycled aluminum & 35 & $70^{*}$ & 1,610 \\
\hline Sheathing & Polycarbonate & 23 & 16 & 1,792 \\
\hline Glazing & Glass & $112^{* *}$ & Total $=$ & $4,558 \mathrm{MJ}\left(1519 \mathrm{MJ} / \mathrm{m}^{2}\right)$ \\
\hline Framing & Lumber & 37 & 10.4 & 93 \\
\hline Sheathing & Plywood & 32 & 30.3 & 333 \\
\hline Insulation & Fiberglass & 14 & 6.1 & 424 \\
\hline Interior Finish & Gypsum wallboard & 30 & 93.3 & 183 \\
\hline Paint & Paint (generic) & 0.6 & 70.0 & 56 \\
\hline Exterior Finish & Vinyl & 4 & Total $=$ & 280 \\
\hline
\end{tabular}

*value estimated based on published data for other plastics

**weight of entire ASI glass panel (data published by Schott Solar). 
and wood-frame walls are much closer. Finally, in terms of embodied energy, the RGWPS requires nearly two-and-a-half times as much energy to produce and install as a typical wood-frame wall.

The following conclusions are drawn from the sustainability analysis:

- Additional thermal and energy analysis is required to optimize RGWPS design (i.e., cross-section shape, materials) and installation (i.e., number of panels to install, location of panels in wall).

- Thermal performance of the RGWPS frame must be improved in order to make it more thermally comparable to conventional wall assemblies.

- RGWPS does not provide significant increase in natural lighting due to low visible transmittance of ASI glazing. The upper portion of the wall may actually not need ASI glazing, thus enhancing visible transmittance.

- The number of RGWPS panels will affect overall energy performance by increasing heating/cooling loads and decreasing electrical loads.

- At approximately $6.7-7.8^{\circ} \mathrm{C}$, the temperature at the interior corner of the RGWPS frame is cold enough to present a condensation issue during cold winter months when interior air is typically warm and humid. The glazing frame should be designed to prevent condensation.

- In the Energy-10 model, the decreased thermal performance of the RGWPS is essentially offset by the energy generated by its PV system.

- The slight reduction in annual energy cost for the RGWPS is negligible, especially when additional maintenance costs for the PV system are considered.

- Sustainability of the RGWPS can be improved by altering material selections and optimizing the structural system to reduce the amount of material needed to build the panels.

- The glazing and polycarbonate contribute most to the embodied energy in the RGWPS.

- Additional analysis should be completed to compare thermal, energy, and materials properties to wall areas with large glazed openings that utilize traditional glazing elements and structural framing. An example would be large picture windows that are similar in size to the RGWPS. The results will likely indicate that the RGWPS is much more competitive with these types of systems versus wood-frame walls with small punched window openings.

The above-described conclusions highlight the need for design changes in the RGWPS in order for it to be more competitive with traditional wall systems in terms of sustainability. One area of significant importance is thermal efficiency. An option to improve thermal efficiency would be to decrease the center of glazing U-factor by adding a translucent and highly insulating material such as aerogel to the air cavity between the glazing and polycarbonate sheathing. Preliminary study of using such insulation material shows good promise [6].

\section{CONFLICT OF INTEREST}

The authors confirm that this article content has no conflict of interest.

\section{ACKNOWLEDGEMENTS}

Declared none.

\section{REFERENCES}

[1] A. Goetzl, and D.B. McKeever, "Building codes - obstacles or opportunities?", Forest Prod. J., vol. 49, no. 9, pp. 12-22, 1999.

[2] C. Arnold, "United States wood frame house construction,"In: Proceedings of the $7^{\text {th }}$ U.S. National Conference on Earthquake Engineering (7NCEE), July 21-25, 2002, Boston, MA, pp. 1-9, 2002.

[3] DOE, "Building energy data book," U.S. Department of Energy, http://buildingsdatabook.eren.doe.gov, 2010 (June 24, 2014).

[4] PATH, "Technology roadmap: advanced panelized construction." Partnership for Advanced Technologies in Housing, Washington, D.C., 2002.

[5] PATH, "Panelized wall systems: making the connections," Partnership for Advanced Technologies in Housing, Washington, D.C., 2006.

[6] J.A. Standley, "Development of a transparent sustainable wall system with load bearing backup framing for residential construction," M.S. Thesis, The Pennsylvania State University, University Park, PA, 2009.

[7] J.A. Standley and A.M. Memari, "Structural assessment of a transparent sustainable wall panel with load-bearing backupframing for residential construction," ASCE J. Archit. Eng., vol. 18, no. 4, pp. 298-314, 2012.

[8] United Nations, "Report of the world commission on environment and development: our common future, "United Nations General Assembly, New York, NY, 1987.

[9] LEED, "LEED for Homes," United States Green Building Council, Washington, D.C., 2008, < http://www.usgbc.org/DisplayPage. aspx?CMSPageID=147> (October 24, 2009).

[10] LEED, “LEED for New Construction," United States Green Building Council, Washington, D.C., 2009, < http://www.usgbc. org/DisplayPage.aspx? CMSPageID=220> (October 24, 2009).

[11] LBNL, "THERM and WINDOW version 5.2," (computer software), Lawrence Berkeley National Laboratory, Berkeley, CA, 2003.

[12] NREL, "Energy-10," (computer software), National Renewable Energy Laboratory, Golden, CO, 2009.

[13] Sheffield Plastics, "Makrolon Polycarbonate Sheet: Fabrication Guide," Sheffield Plastics, Sheffield, MA, 2003.

[14] T. Ariosto and A.M. Memari, "Comparative Study of Energy Efficiency of Glazing Systems for Residential and Commercial Buildings,'In: Proceedings of 2013 Architectural Engineering Conference, University Park, PA, April 3-5, 2013, pp. 408-417, 2013.

[15] Schott Solar, "ASI-Glass Modular Sizes," Schott North America, Inc., Elmsford, NY, 2008.

[16] ORNL, "ORNL Whole Wall R-value Calculator," (computer software), <http://www.ornl.gov/sci/roofs+walls/AWT/Interactive Calculators/NS/Calc.htm>Oak Ridge National Laboratory, Oak Ridge, TN, 2004. (June 24, 2014).

[17] R. Perez, L. Burtis, T. Hoff, S. Swanson, and C. Herig, "Quantifying residential PV economics in the US - payback vs. ccash flow determination of fair energy value," Solar Energy, vol. 77, no. 4, pp. 363-366, 2004.

[18] T. Miyazaki, A. Akisawa, and T. Kashiwagi, "Energy savings of office buildings by the use of semi-transparent solar cells for windows," Renewable Energy, vol. 30, no. 3, pp. 281-304, 2005. 
[19] ATHENA, "ATHENA impact estimator for buildings version 4.0," (computer software), The Athena Institue, Kutztown, PA, 2008.

[20] C.J. Kibert, "Sustainable construction: green building design and delivery," John Wiley and Sons, Inc., Hoboken, N.J, 2007.

[21] TONSCIG, "Using the natural step framework toward the construction and operation of fully sustainable buildings," The
Oregon Natural Step Construction Industry Group, Portland, OR, 2004.

[22] A. Alcorn, "Embodied Energy and $\mathrm{CO}_{2}$ Coefficients for NZ Building Materials," Victoria University of Wellington Center for Building Performance Research, 2001, http://www.victoria.ac.nz/ architecture/centres/cbpr/resources /pdfs/ee-co2_report_nov2001. pdf. (June 24, 2014).

Received: March 27, 2014

(C) Standley and Memari; Licensee Bentham Open.

This is an open access article licensed under the terms of the Creative Commons Attribution Non-Commercial License (http://creativecommons.org/licenses/by-nc/3.0/) which permits unrestricted, non-commercial use, distribution and reproduction in any medium, provided the work is properly cited. 